\title{
On the combinations of silicium
}

\section{Pierre}

To cite this article: I. Pierre (1848) On the combinations of silicium, Philosophical Magazine Series 3, 33:220, 162-163, DOI: 10.1080/14786444808646069

To link to this article: http://dx.doi.org/10.1080/14786444808646069

曲 Published online: 30 Apr 2009.

Submit your article to this journal $2 \pi$

Џll Article views: 1

Q View related articles $₫$ 
He remarks, as an objection to the binocular construction, that the observation will not be convenient, if objects of very different altitudes are to be viewed, but still thinks that it would be worthy of trial in certain cases.

\section{Intelligence and Miscellaneous Articles.}

\section{on the Combinations of SILICIUM. BY I. PIERRE.}

$\mathbf{D}^{\circ}$ OUBTS are still enteriained as to the formula which should be assigned to silicic acid, and consequently to the chloride of silicium. Some chemists admit that silicic acid should be represented by the formula $\mathrm{SiO}^{3}$, and adopt the number $266^{\circ} 82$ as the equivalent of silicium; others prefer the formula $\mathrm{SiO}^{2}$, taking $\mathrm{Si}=177 \cdot 88$. Lastly, some are of opinion that the rational formula of silicic acid is SiO, and the equivalent of silicium 88.94 .

The first of these formulæ, admitted by the majority of mineralogists, has the imposing authority of Berzelius, Thenard, \&c. The formula $\mathrm{SiO}^{2}$, adopted by a certain number of German chemists and mineralogists, among whom may be mentioned M. Gmelin, possesses the advantage, according to $M$. Cahours, of making the volume of vapour representing the equivalent of the protosilicate of ethyle of M. Ebelmen enter within the ordinary conditions. Lastly, the formula $\mathrm{SiO}$ seems at present to be generally admitted by the majority of French chemists; it was proposed long since by M. Dumas, when he published his beautiful investigation upon the specific gravities of vapours. M. Ebelmen, in bis interesting memoir upon silicic æthers, has adopted this latter opinion after a very learned and profound discussion.

As the curious facts of the ærherification of silicic acid do not appear to have resolved the question completely in the eyes of a certain number of chemists, I proposed in the present investigation to ascertain whether it might not be possible to obtain, either by some facts of substitution or by the production of some double chlorides analogous to the double fluorides already known, or lastly, by the production of some new æther or amidogen compounds, results of such a nature as would allow chemists to base their selection upon more explicit and varied data.

The difficulties encountered in the preparation of the majority of these various kinds of compounds, the long and tedious manipulations required by researches of this class, in which the chloride of silicium is the first indispensable material, -all these circumstances combined did not admit of my varying and multiplying the operations to the extent I desired; but imperfect and incomplete as they are, I think they deserve to fix for a moment the attention of chemists.

I. Compounds derived by Substitution from the Chloride of Silicium.- The facts exposed in this first part of my investigation may be resumed in the following propositions:-

1. The chloride of silicium may be deprived, at a high temperature, by the action of hydrosulphuric acid, of the whole of its chlorine, and the latter replaced by an equivalent quantity of sulphur, 
passing through a series of intermediate compounds containing silicium, chlorine and sulphur.

2. The first of these intermediate compounds, the body $\mathrm{SiSCl}^{2}$, is readily isolated on account of its great stability.

3. The sulphuret of silicium may likewise be obtained perfectly pure.

4. The existence of the compound $\mathrm{SiS}^{2} \mathrm{Cl}$ is rendered highly probable from certain reactions which take place between alcohol or wood-spirit and the intermediate chlorosulphuretted products.

In concluding this short notice, it may perhaps not be uninteresting to arrange in a coinparative table the expressions representing these different compounds, according to each of the three views of the molecular constitution of the chloride of silicium:

\begin{tabular}{|c|c|c|c|}
\hline Chloride of silicium... & $\begin{array}{l}\mathrm{Si}=266 \cdot 82 . \\
\mathrm{SiCl}^{3}\end{array}$ & $\begin{array}{l}\mathrm{Si}=177 \cdot 88 \\
\mathrm{SiCl}^{8}\end{array}$ & $\begin{array}{l}\mathrm{Si}=88 \cdot 94 \\
\mathrm{SiCl}\end{array}$ \\
\hline Chlorosulphuret .... & $\mathrm{SiSCl}^{2}$ & $\mathrm{Si}^{3} \mathrm{~S}^{2} \mathrm{Cl}^{+}$ & $\mathrm{Si}^{3} \mathrm{SCl}^{2}$ \\
\hline Chlorobisulphuret & - $\mathrm{SiS}^{2} \mathrm{Cl}$ ? & $\mathrm{Si}^{3} \mathrm{~S}^{4} \mathrm{Cl}^{2}$ ? & $\mathrm{Si}^{3} \mathrm{~S}^{2} \mathrm{Cl} ?$ \\
\hline Sulphuret. . . . . . & $\mathrm{SiS}^{3}$ & $\mathrm{SiS}^{2}$ & SiS \\
\hline
\end{tabular}

If regularity and simplicity deserve to be taken into consideration, the preference will undoubtedly be given to the first series with $\mathrm{Si}=266.82$. Comptes Rendus, May 15, 1848.

\section{ON THE CONSTITUTION OF THE PHOSPHATES OF THE ORGANIC ALKALIES. BY DR. THOMAS ANDERSON,}

The author had been led to investigate the phosphates of the organic alkalies, with the view of determining the accuracy of an analysis of the phosphate of strychnia by Regnault, which gave results incomparable with the known constitution of the organic phosphates. He alluded to the investigation of the phosphates of aniline by Nicholson, and proceeded to the statement of his own observations.

Phosphate of Strychnia, with one equivalent of strychnia, was obtained in long truncated needles, by digesting strychnia in tribasic phosphoric acid. It dissolved readily in water, and was acid to testpaper. By analysis it gave results corresponding to the formula $\left(\mathrm{C}^{44} \mathrm{H}^{23} \mathrm{~N}^{2} \mathrm{O}^{4} \mathrm{HO}\right) 2 \mathrm{HO}^{3} \mathrm{PO}^{5}$.

The crystallized salt was found to contain four equivalents of water of crystallization.

Phosphate of Strychnia, with two equivalents of strychnia.-Bylongcontinued digestion of strychnia with the foregoing water in solution, an additional atom of the alkaloid is dissolved, and the solution on cooling deposits rectangular tables of a salt which is neutral to test-paper. It is less soluble in water than the acid phosphate, and its constitution was found to be represented by the formula $2\left(\mathrm{C}^{44} \mathrm{H}^{23}\right.$ $\left.\mathrm{N}^{2} \mathrm{O}^{4} \mathrm{HO}\right) \mathrm{HO}^{2} \mathrm{PO}^{5}$.

Phosphate of Brucia, with two equivalents of brucia, is obtained by the solution of brucia in phosphoric acid, and crystallizes from the concentrated solution in short prisms. The crystals are neutral to test-paper, and contain a large quantity of water of crystallization, which they lose by efflorescence. The formula of the salt is $2\left(\mathrm{C}^{44}\right.$ 